\title{
EFECTOS DEL TIPO DE CARBOHIDRATO SOBRE LA CAPTURA DE NITRÓGENO Y PRODUCCIÓN DE LECHE BOVINA
}

\section{EFFECTS OF TWO CARBOHYDRATE SOURCES ON NITROGEN CAPTURE AND ON PRODUCTIVE PERFORMANCE IN DAIRY COWS}

\author{
Manterola, H.B. ${ }^{1}$; Carreño, N.G. ${ }^{2}$; Orellana, M.C. ${ }^{1}$; González, H.V. ${ }^{1}$ y Cerda, D.A. ${ }^{1}$ \\ 'Departamento de Producción Animal. Facultad de Ciencias Agronómicas. Universidad de Chile. Santiago. \\ Chile.hmantero@gmail.com \\ 2Universidad Nacional Abierta y a Distancia, UNAD. Escuela de Ciencias Agrícolas Pecuarias y del Medio \\ Ambiente.Programa de Especialización en Nutrición Animal Sostenible. Bogotá, Colombia.nelizcg@gmail.com
}

\section{Palabras clave adicionales}

Suplementación. Urea en leche.

\section{RESUMEN}

El estudio tuvo por objetivo determinar si la suplementación con dos fuentes de carbohidratos de distinta tasa de degradación disminuía la concentración de amoníaco al incrementar la captura de nitrógeno por las bacterias ruminales en vacas en lactancia, pastoreando ballica perenne (Lolium perenne), con alto contenido de proteína. Se utilizaron 4 vacas con cánula ruminal distribuidas en 4 tratamientos con distintas proporciones de maíz:avena, como suplemento: T0 (control): sin suplementación; T1: 80:20; T2: 50:50 y T3: 20:80. Se utilizó un diseño de cuadrado latino de 4 x 4 y los efectos se midieron en la concentración de amoníaco ruminal, amoníaco y urea en sangre y urea en leche además de producción y composición de la leche. La pastura de ballica perenne presentó un $23 \%$ de proteína bruta y $14,4 \mathrm{MJ}^{*} \mathrm{~kg}^{-1}$ de energía metabolizable.El aporte energético en los tratamientos con suplementación fue similar, ajustando la cantidad de suplemento diario. Los tratamientos con suplementación, a excepción del T3, presentaron una concentración de amoníaco ruminal menor $(p<0,05)$, que la del testigo $(19,8$; 13,$1 ; 10,6$ y $14,6 \mathrm{mg}^{*} \mathrm{dL}^{-1}$, para T0, T1, T2 у T3 respectivamente) sin diferencias entre los tratamientos con suplementación ( $p>0,05)$. Tampoco hubo diferencias $(p>0,05)$ para concentraciones de amoníaco plasmático, urea plasmática, producción de leche, contenido de grasa, proteína, energía y urea en leche. El suministro de mezclas de maíz y avena a vacas en praderas de ballica de

\author{
AdDitiONAL KEYWORDS \\ Milk urea. Supplementation.
}

alto contenido de proteína degradable, reduce la concentración de amoníaco ruminal, pero este efecto no se traduce en mayores producciones de leche o cambios en sus componentes.

\section{SUMMARY}

The objective of this study was to determine if the supplementation with two carbohydrate sources that have different degradation rates, reduces the ammonia production by ruminal bacteria by increasing the nitrogen capture in dairy cows grazing high protein contents pastures. Four dairy cows fitted with ruminal cannulas were randomly assigned to four treatments, corresponding to different proportion of corn:oat: T0 (control): grazing without supplementation; T1: 80:20; T2: 50:50 and T3: 20:80. Pasture consisted of perennial ryegrass (Lolium perenne) with $23 \%$ crude protein and $14,4 \mathrm{MJ}^{*} \mathrm{~kg}^{-1}$, and the effects were measured on ruminal ammonia concentration, blood ammonia and urea, and milk production and composition (protein, fat and urea). Energy supply was made similar by changing the amount given. A $4 \times 4$ latin square design was used. The supplementation with carbohydrate sources independent of treatments, significantly reduced ammonia concentration $(p<0,05)$ and no significant effects among supplemented treatments were found $\left(19.8,13.1,10.6\right.$ and $14.6 \mathrm{mg}^{*} \mathrm{dL}^{-1}$ for T0, T1, $\mathrm{T} 2$ and $\mathrm{T} 3$ respectively). No significant differences 


\section{MANTEROLA, CARREÑO, ORELLANA, GONZÁLEZY CERDA}

$(p>0,05)$ were found neither for plasma ammonia and urea nor for milk production, milk fat and protein, milk energy and milk urea content. It is concluded that supplementation with mixtures of corn and oat grains to dairy cows grazing ryegrass pastures with high protein content reduces rumen ammonia concentration but do not affect milk production, milk components and milk urea.

\section{INTRODUCCIÓN}

El alto precio de los concentrados, han obligado a muchos productores intensivos de leche a derivarse a sistemas basados en pastoreo de praderas de ballica perenne (Lolium perenne), que durante el crecimiento primaveral presentan elevados contenidos de proteína bruta (en muchos casos sobrepasa el $20 \%$ ) que es altamente degradable y genera elevadas concentraciones de amoníaco en rumen, que sobrepasan el potencial de captación por parte de las bacterias del rumen. Esta asincronía entre las concentraciones de amoníaco y la disponibilidad de energía deriva en una baja eficiencia del uso de las proteínas dietarias por las bacterias ruminales (Keim y Anrique, 2011; Gehman et al., 2006; Bach et al., 2005) ya que el exceso de amoníaco se difunde al sistema circulatorio y es transportado al hígado donde debe ser convertido en urea, lo que implica un gasto energético adicional y una mayor concentración de urea en leche que afecta a su calidad (Keim y Anrique, 2011; Frank et al., 2002; Alvarez etal., 2006). La adición a la dieta, de mezclas de diferentes granos de cereales, ha demostrado ser efectiva para mejorar la eficiencia de utilización del amoníaco generado, ya que aportan tanto energía como cadenas carbonadas en diferentes tiempos dependiendo de la tasa de degradación que posean (Kolver y Muller, 1998; Gehman et al., 2006), por ello, la mezcla de dos o más cereales debería traducirse en mayor captación de amoníaco por las bacterias ruminales y por lo tanto, mayor tasa de síntesis proteica microbial.

El maíz y la avena son cereales que comúnmente se utilizan en las raciones para vacunos lecheros, con resultados positivos en la captación de amoníaco por las bacterias (Keim y Anrique, 2011) con la consiguiente mayor eficiencia de uso del nitrógeno, mayor síntesis proteica microbial, mayor síntesis proteica en glándula mamaria y mayor cantidad de leche producida, con menor contenido de urea (Reis y Combs, 2000; Robaina et al.,1998). Los estudios de Jahn et al. (1996); Hristov et al. (2005) y Pulido et al. (2009), confirman esta hipótesis registrando incrementos significativos, en síntesis proteica microbial y mayor síntesis proteica en la glándula mamaria; sin embargo, las respuestas en producción de leche no han sido consistentes. Por lo tanto, el objetivo de este trabajo fue cuantificar los efectos de suplementar, con diferentes proporciones de grano de maíz y avena, a vacas en lactancia, pastoreando praderas de ballica, sobre las concentraciones de amoníaco ruminal, amoníaco sanguíneo y de urea en sangre y leche, así como determinar los efectos sobre la producción y composición de leche.

\section{MATERIAL Y MÉTODOS}

El estudio se realizó en la Estación Experimental Oromo del Departamento de Producción Animal, Facultad de Ciencias Agronómicas de la Universidad de Chile, Región de los Lagos, durante los meses de noviembre y diciembre con vacas pastoreando praderas de ballica bianual de primer año y en estado vegetativo. La fase experimental se realizó durante 24 días. Se utilizaron 24 vacas de raza Holstein neozelandesa, de similar fecha de parto y nivel de producción, 4 de ellas provistas de cánula en rumen, las cuales se rotaron entre los tratamientos en un diseño de cuadrado latino de $4 \times 4$. Las otras 20 se asignaron al azar entre los distintos tratamientos (T0: tratamiento control, vacas en pastoreo en praderas de ballica sin suplementación; T1: suplementación con una mezcla de maíz ( $80 \%$ ) y avena $(20 \%)$; T2: suplementación con una mezcla de maíz 


\section{CARBOHIDRATOS, CAPTURA DE NITRÓGENO Y PRODUCCIÓN DE LECHE BOVINA}

$50 \%$ y avena $50 \%$; T3: suplementación con mezcla de maíz $20 \%$ y avena $80 \%$ ). La cantidad de suplemento aportado se determinó tomando como base el $\mathrm{T} 2$ a razón de 4 $\mathrm{kg}$ /animal al día. La cantidad ofertada en el resto de los tratamientos, se ajustó de manera tal que realizaran un aporte de energía similar a T2. Se suministraron bloques de sal mineral durante el pastoreo. En los dos últimos días de cada período $(\mathrm{P})$ se tomaron muestras de contenido ruminal, sangre y leche, en los ordeños de la mañana (5:00 a.m.) y tarde (4:00 p.m). En las muestras de contenido ruminal, se midió la concentración de amoníaco; en las de sangre, amoníaco y urea, y en las de leche, proteína, grasa y urea. Semanalmente se midió la cantidad de leche producida por vaca y tratamiento. La degradabilidad de la materia seca y proteína de la pradera y del concentrado, se midió durante 4 períodos de muestreo, incubando las muestras en el rumen según método propuesto por Orskov y McDonald (1979), utilizando tres vacas fistuladas en rumen y ocho tiempos de incubación.

A todas las muestras se les determinó materia seca (MS), proteína (PB), fibra detergente neutro (FDN) y cenizas (C). Para comparar los efectos de tratamiento sobre la producción y composición de leche, se utilizó un diseño completamente al azar. Para comparar los efectos de tratamiento sobre las variables ruminales y sanguíneas se utilizó un diseño de cuadrado latino 4 x 4, con cuatro periodos ( 6 días cada uno y 4 tratamientos). El efecto residual de tratamiento, se corrigió dejando cinco días entre período durante los cuales las vacas solo pastorearon la pradera. Para los estudios de degradabilidad se utilizaron tres vacas fistuladas en rumen con cánula ruminal. Para el análisis estadístico de las variables estudiadas se utilizó el programa SAS. Las medias de los tratamientos fueron comparados por el test de Tukey, con un nivel de significancia del $5 \%$. Se establecieron ecuaciones de regresión entre proporciones de maíz y avena y respuestas en parámetros ruminales y en producción y composición de leche. Las ecuaciones de regresión para la degradabilidad de la MS de la pastura y suplementos y de la degradabilidad de la proteína, se sometieron a una prueba $t$ de Student para detectar diferencias significativas entre los coeficientes de las ecuaciones obtenidas.

\section{RESULTADOSYDISCUSIÓN}

\section{COMPOSICIÓN QUÍMICA DE LA PRADERA Y SUPLEMENTOS}

La pastura de ballica mostró valores de proteína bruta superiores al $20 \%$, durante los 4 periodos del experimento (tabla I) con $22,3 \%$ de PB y $14,4 \mathrm{Mj}^{*} \mathrm{~kg}^{-1}$ de energía metabolizable (EM) como promedio, valores similares a lo reportado por Pulido et al. (2009), quienes determinaron contenido de $22,4 \%$ PB y $13,8 \mathrm{Mj}^{*} \mathrm{~kg}^{-1}$ para praderas similares en la misma zona y estación del año. Estos valores de PB están por encima de los requerimientos de las vacas en lactancia, lo que sumado a su alta degradabilidad, explica las altas concentraciones de amoníaco registradas en los bovinos pastoreando este tipo de praderas. No se presentaron diferencias significativas entre períodos para PB ni EM ni FDN, aunque se observa una tendencia a aumentar el contenido de PB desde el P1 hasta el P3, así como también la FDN presenta un alza entre el P2 y P3, este último con los valores más altos de PB y FDN. Se destacan los bajos valores de FDN, comparados con los reportados por Pulido et al. (2009) de $51 \%$, atribuibles al estado fenológico más atrasado en la pradera de este estudio. En cuanto al extracto etéreo (EE) el valor más alto se presentó en el período 4 , siendo significativamente superior $(\mathrm{p}<0,05)$ al P1. El maíz y la avena utilizados presentaron contenidos de proteína bruta de 6,4 y $13 \%$ respectivamente y de energía metabolizable de 10,35 y 15,05 $\mathrm{MJ} * \mathrm{~kg}^{-1}$ respectivamente, valores que están dentro de los rangos descritos para estos granos en diversas tablas de compo- 


\section{MANTEROLA, CARREÑO, ORELLANA, GONZÁLEZY CERDA}

Tabla I. Composición nutritiva (media \pm error estándar) de la pradera y de las mezclas de maíz y avena. (Nutritive composition (mean \pm standar error) of pasture and of corn-oat mixture).

\begin{tabular}{lccccccc}
\hline & \multicolumn{4}{c}{ Pradera } & \multicolumn{4}{c}{ Mezcla maíz:avena } \\
& P1 & P2 & P3 & P4 & $80: 20$ & $50: 50$ & $20: 80$ \\
\hline MS (\%) & 6,3 & 6,3 & 5,2 & 5,1 & 89,7 & 89,6 & 89,3 \\
PB (\%) & $20,6 \pm 2,8$ & $22,4 \pm 3,5$ & $23,3 \pm 4,2$ & $22,7 \pm 3,9$ & $8,3 \pm 0,3$ & $9,6 \pm 0,2$ & $11,7 \pm 0,5$ \\
EE (\%) & $2,8 \pm 0,3$ & $4,0 \pm 0,5$ & $3,8 \pm 0,4$ & $4,4 \pm 0,6$ & $3.5 \pm 0.08$ & $3,9 \pm 0,07$ & $4,3 \pm 0,05$ \\
EM (MJ*kg-1 ( $^{2}$ & 14,6 & 14,0 & 14,3 & 14,6 & 12,4 & 11,9 & 11,3 \\
FDN (\%) & $41,7 \pm 4,5$ & $37,8 \pm 5,4$ & $45,3 \pm 6,1$ & $42,0 \pm 3,8$ & $32,8 \pm 2,3$ & $37,1 \pm 3,5$ & $38,1 \pm 3,7$ \\
\hline
\end{tabular}

Análisis realizado en el Laboratorio de Nutrición Animal, Departamento de Producción Animal de la Facultad de Ciencias Agronómicas, Campus Antumapu, Universidad de Chile. ${ }^{1}$ MicroKjeldahl. ${ }^{2}$ calculados a partir de la energía bruta (calorímetro) y ponderada por la digestibilidad de la MS para luego aplicar el factor 0,84 .

$\mathrm{P}=$ periodo; $\mathrm{MS}=$ materia seca; $\mathrm{PB}=$ proteína bruta; $\mathrm{EE}=$ extracto etéreo; $\mathrm{EM}=$ energía metabolizable; $\mathrm{FDN}=$ fibra detergente neutro.

sición de alimentos de Chile (FIA-UACH, 1995).

\section{DEGRADABILIDAD DE LA MS Y PB DE LA PRADERA Y DE LAS MEZCLAS}

Los valores de la fracción soluble $a, b$ y $a+b$ de la MS de la pradera presentaron diferencias significativas $(\mathrm{p}<0,05)$ entre los cuatro períodos de muestreo, presentando el período 1 el mayor valor de la fracción soluble $a$, respecto a los otros $(\mathrm{p}<0,05)$, no presentándose diferencias para este valor entre los períodos 2, 3 y 4 (tabla II). El valor $c$ no presentó diferencias significativas entre tratamientos. Estos valores para los distintos períodos son mayores a los reportados por Pulido et al. (2009) de 41,5\% y de Valderrama y Anrique (2011) de 44,3\%, para pradera con similar composición botánica, lo cual sería indicativo de un estado más juvenil de esta pradera. Respecto a la fracción $b$ se presentaron diferencias significativas $(\mathrm{p}<0,05)$ entre el período 1 y 3 y entre el período 2 y 4 . Estos valores son bajos comparados con los reportados por otros autores para similares praderas que fluctúan entre 56 y $58 \%$. Al respecto, Van Vuuren et al. (1991), señalan que las gramíneas perennes (Lolium perenne) a comienzos de primavera presentan altos valores de la fracción soluble que se encuentran asociados con baja concentración de FDN y altas proporciones de hoja/tallo. Estudios realizados por Pulido et al. (2009) en el sur de Chile en praderas compuestas en un 70,4\% por Lolium perenne, determinaron valores de $52,26 \%$ para la fracción $a$; $42,71 \%$ para $b$ y $94,07 \%$ en $a+b$ de la materia seca, Pulido et al. (2009) para este mismo tipo de praderas, reportaron valores para $a$ de $29,9 \%$; $b$ de $48,7 \%$ y para $a+b$ de $78,6 \%$ para MS de praderas de Lolium perenne, lo que indica la variación que entre años puede apreciarse para la degradabilidad de estas pasturas.

La degradabilidad real de la MS de la pradera, para una tasa de pasaje de $0,08 \% / \mathrm{h}$ con una promedio entre períodos de $64,6 \%$, no presentó diferencias significativas entre períodos $(p>0,05)$ con valores menores (tabla II) a los reportados por Pulido et al. (2009) quien obtuvo $75,6 \%$ con un $k$ de $0,08 \% * \mathrm{~h}^{-1}$. La degradabilidad real de la PB de la pradera fue significativamente menor $(p<0,05)$ en el período 2 respecto a los otros 3 períodos (tabla II) siendo estos valores inferiores a los reportados por Valderrama y Anrique (2011) de $97 \%$ con $k$ de $0,06 \% \mathrm{~h}^{-1}$ para una 


\section{CARBOHIDRATOS, CAPTURA DE NITRÓGENO Y PRODUCCIÓN DE LECHE BOVINA}

Tabla II. Promedios ( \pm error estándar) de parámetros de degradabilidad de la MS y de la $P B$ en la pradera de ballica perenne. (Degradability parameters of DM and CP (mean \pm standar error) in rye grass pasture).

\begin{tabular}{lcccc}
\hline & $a \%$ & $b \%$ & $a+b \%$ & $c$ \\
\hline $\begin{array}{l}\text { Degradabilidad de la PB } \\
\text { Período 1 }\end{array}$ & $68,6 \pm 4,2^{\mathrm{a}}$ & $14,2 \pm 1,1^{\mathrm{a}}$ & 82,7 & $0,31 \pm 0,05^{\mathrm{a}}$ \\
Período 2 & $51,4 \pm 3,4^{\text {bd }}$ & $7,8 \pm 0,6^{\mathrm{b}}$ & 59,2 & $0,22 \pm 0,01^{\mathrm{a}}$ \\
Período 3 & $52,6 \pm 4,5^{\text {cd }}$ & $17,6 \pm 1,2^{\mathrm{a}}$ & 70,2 & $0,24 \pm 0,02^{\mathrm{a}}$ \\
Período 4 & $55,5 \pm 4,5^{\mathrm{d}}$ & $7,2 \pm 0,3^{\mathrm{bc}}$ & 62,7 & $0,19 \pm 0,01^{\mathrm{a}}$ \\
Promedio & 57,0 & 11,7 & 68,7 & 0,24 \\
& & & & \\
Degradabilidad de la MS & & & 95,6 & $0,069 \pm 0,006^{\mathrm{a}}$ \\
Período 1 & $39,3 \pm 2,3^{\mathrm{a}}$ & $56,3 \pm 3,8^{\mathrm{a}}$ & 99,1 & $0,064 \pm 0,004^{\mathrm{bd}}$ \\
Período 2 & $39,9 \pm 2,1^{\mathrm{b}}$ & $59,2 \pm 3,2^{\mathrm{b}}$ & 90,0 & $0,061 \pm 0,007^{\mathrm{c}}$ \\
Período 3 & $38,8 \pm 2,5^{\text {ad }}$ & $51,2 \pm 2,5^{\mathrm{c}}$ & 99,8 & $0,064 \pm 0,005^{\mathrm{dc}}$ \\
Período 4 & $38,4 \pm 2,8^{\text {cd }}$ & $61,4 \pm 4,5^{\mathrm{d}}$ & 96,1 & 0,064 \\
Promedio & 39,1 & 57,0 & 96,1 & \\
\hline
\end{tabular}

*Letras en la columna indican diferencias significativas $(p \leq 0,05)$ entre períodos para cada parámetro. $c=$ tasa constante de desaparición de la fracción $b$ por hora.

pradera de ballica en estado vegetativo.

La fracción soluble $a$, fue inferior $(\mathrm{p}<0,05)$ en el maíz que en la avena (tabla III), sin embargo, la fracción insoluble potencialmente degradable del maíz $(b)$ fue significativamente superior $(\mathrm{p}<0,05)$, lo cual se explica por la mayor solubilidad de las proteínas y almidones constituyentes del grano de avena permitiendo una complementación de estos granos en la entrega de energía y cadenas carbonadas a los microorganismos, para una mayor captación del amoníaco en rumen (Stokes et al., 1991; Hristrov y Ropp, 2003; Gehman et al., 2006). Es así que a medida que se incrementa la proporción de avena sobre maíz en las mezclas, la fracción $a$ va aumentando y la fracción $b$ va disminuyendo (tabla III).

Tabla III. Promedios ( \pm error estándar) de parámetros de la degradabilidad de la materia seca de los concentrados. (Dry matter degradability (mean \pm standar error) of concentrates).

\begin{tabular}{lcccc}
\hline \multirow{2}{*}{ Suplemento } & \multicolumn{4}{c}{$\begin{array}{c}\text { Parámetros de la degradabilidad de la MS } \\
b+b \%\end{array}$} \\
\hline Maíz & $a \%$ & $b \%$ & 99,8 & $0,084 \pm 0,009^{\mathrm{a}}$ \\
Avena & $37,5 \pm 2,6^{\mathrm{A}}$ & $62,3 \pm 5,1^{\mathrm{A}}$ & 83,8 & $0,13 \pm 0,01^{\mathrm{B}}$ \\
$80 \%$ maíz/20\%avena & $68,3 \pm 4,8^{\mathrm{B}}$ & $16,8 \pm 1,4^{\mathrm{B}}$ & 98,4 & $0,076 \pm 0,008^{\mathrm{a}}$ \\
$50 \%$ maíz/50\%avena & $46,1 \pm 3,5^{\mathrm{a}}$ & $52,4 \pm 4,2^{\mathrm{a}}$ & 92,1 & $0,1 \pm 0,01^{\mathrm{b}}$ \\
$20 \%$ maíz/80\%avena & $55,4 \pm 4,5^{\mathrm{b}}$ & $36,6 \pm 2,4^{\mathrm{b}}$ & 88,8 & $0,079 \pm 0,007^{\mathrm{a}}$ \\
\hline
\end{tabular}

A,B Letras mayúsculas en la columna indican diferencias significativas $(p<0,05)$ entre granos para cada parámetro; a,bLetras minúsculas indican diferencias significativas entre mezclas para cada parámetro. $c=$ tasa constante de desaparición de la fracción $b$ por hora. 


\section{MANTEROLA, CARREÑO, ORELLANA, GONZÁLEZY CERDA}

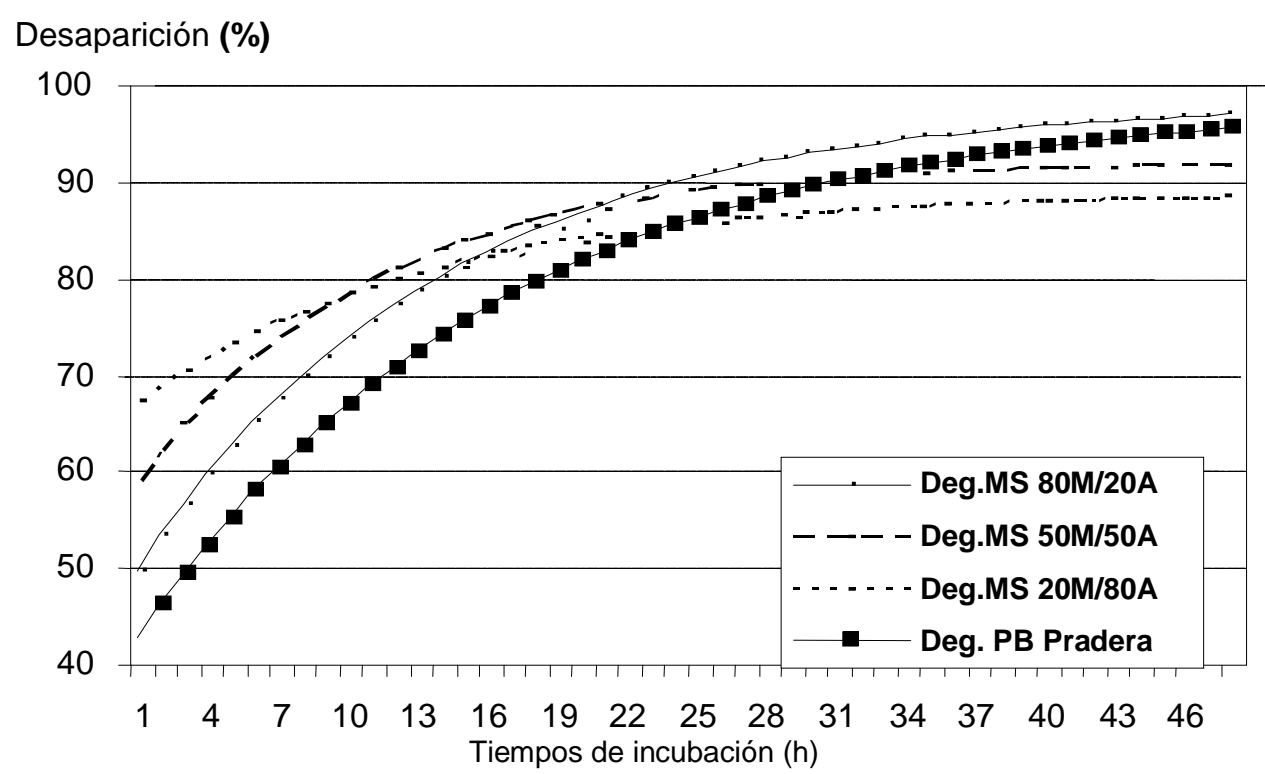

Figura 1. Degradabilidad de la MS de la pradera y de las distintas proporciones de maíz y avena. (Dry matter degradability in pasture and different proportions of corn and oat).

La mezcla del T1 (80M20A), presentó una degradabilidad $a+b$ significativamente mayor (tabla III y figura 1) que las otras mezclas, lo cual se debe a la mayor presencia del maíz, que a pesar de presentar un menor valor $a$ el valor $b$ fue muy superior al de la avena.

\section{EFECTO SOBRE CONCENTRACIÓNDE AMO- NÍACO RUMINAL}

La concentración de amoníaco de la mañana, no difirió significativamente de la de la tarde (tabla IV). La concentración promedio del amoníaco por día, disminuyó significativamente $(\mathrm{p}<0,05)$ respecto al tratamiento control, al utilizar las mezclas del T1 y T2, no así con la mezcla del T3, en que la concentración fue similar a las de T0 (tabla IV). En el T2, la concentración de amoníaco ruminal se redujo en $46,5 \%$ respecto a T0 en el T1, ésta disminuyó en $33,6 \%$ y el T3 en $26,38 \%$ con relación al tratamiento control. Este comportamiento refleja la mayor captación de amoníaco por

Tabla IV. Efecto de los tratamientos sobre la concentración (media \pm error estándar) de amoníaco ruminal. (Effects of treatments on ruminal ammonia concentration (mean \pm standar error)).

\begin{tabular}{|c|c|c|c|c|}
\hline & $\begin{array}{c}\text { T0 } \\
\text { Sin suplemento }\end{array}$ & $\begin{array}{c}\text { T1 } \\
80: 20\end{array}$ & $\begin{array}{c}\text { T2 } \\
50: 50\end{array}$ & $\begin{array}{c}\text { T3 } \\
20: 80\end{array}$ \\
\hline $\mathrm{NH}_{3}$ ruminal $\mathrm{AM}\left(\mathrm{mg} \cdot \mathrm{dl}^{-1}\right)$ & $18,2 \pm 2,1^{\mathrm{a}}$ & $13,2 \pm 1,1^{b}$ & $9,1 \pm 0,8^{b}$ & $15,6 \pm 1,3^{a b}$ \\
\hline $\mathrm{NH}_{3}$ ruminal $\mathrm{PM}\left(\mathrm{mg} \cdot \mathrm{dl}^{-1}\right)$ & $21,5 \pm 1,8^{a}$ & $13,1 \pm 0,9^{b}$ & $12,1 \pm 1,0^{\mathrm{b}}$ & $13,5 \pm 1,0^{\mathrm{b}}$ \\
\hline promedio $\left(\mathrm{mg}^{\mathrm{dl}} \mathrm{dl}^{-1}\right)$ & $19,8 \pm 1,7^{a}$ & $13,1 \pm 1,2^{\mathrm{b}}$ & $10,6 \pm 0,9^{b}$ & $14,6 \pm 1,2^{\mathrm{ab}}$ \\
\hline
\end{tabular}

$a, b$ Letras diferentes sobre la línea indican diferencias significativas $(p<0,05)$. 


\section{CARBOHIDRATOS, CAPTURA DE NITRÓGENO Y PRODUCCIÓN DE LECHE BOVINA}

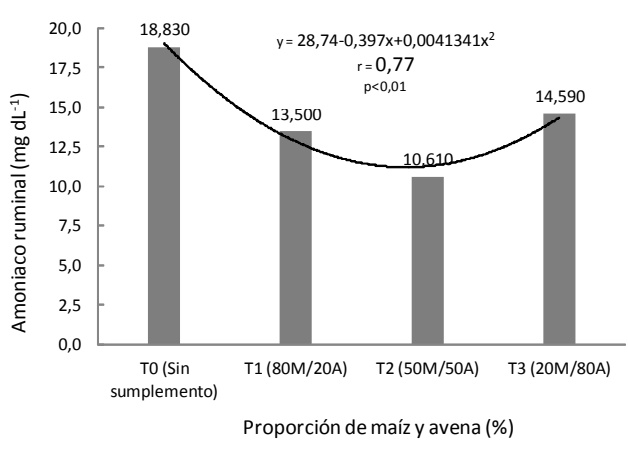

Figura 2. Variación del amoniaco ruminal en vacas fistuladas y suplementadas con maízavena en distintas proporciones. (Variation of ruminal ammonia in fistulated dairy cows supplemented with corn-oat in different proportions).

las bacterias, con la mezcla de $50 \% \mathrm{M}: 50 \% \mathrm{~A}$ (T2) al aportar en forma más sincronizada las cadenas carbonadas y energía en relación a la curva de degradación de las proteínas dietarias (Hristov y Ropp, 2003; Gehman et al., 2006).

Al hacer una regresión de los efectos de tratamiento sobre el amoníaco ruminal estos se ajustaron a una ecuación de tipo cuadrático $(\mathrm{p}<0,05)$ (figura 2), presentando una disminución significativa del amoníaco ruminal a medida que se aumentó la proporción de avena hasta $50 \%$, para luego au- mentar al incluir $80 \%$ de avena. Lo anterior se explica por el aporte de energía más rápido que haría la avena durante las primeras horas después de la ingestión, lográndose una mayor sincronización entre la degradación de la fracción proteica de la dieta con el aporte energía y cadenas carbonadas de los granos (Jhan et al., 1996).

\section{EFECTOSOBRE LAS CONCENTRACIONESDE $\mathrm{NH}_{3}$ Y UREA PLASMÁTICA \\ No se presentaron diferencias significa-} tivas $(\mathrm{p}<0,05)$ entre tratamientos, así como tampoco entre horarios (mañana y tarde) dentro de tratamiento, tanto para concentración de amoníaco o urea plasmática (tabla V). Al ajustar la regresión de los efectos de tratamiento sobre las concentraciones de $\mathrm{NH}_{3}$ y urea plasmática, a un modelo cuadrático $(p<0,01)$ (figura 3 y 4$)$, se observa una disminución significativa $(p<0,01)$ del amoníaco y de la urea en los tratamientos que incluyeron granos, respecto a T0. Además, la concentración de amoníaco y urea en plasma se reduce al aumentar la fracción de avena.

\section{EFECTO SOBRELAPRODUCCIÓNYCOMPOSI- CIÓNDELALECHE}

No se presentaron diferencias significativas $(p>0,05)$ en producción de leche así

Tabla $\boldsymbol{V}$. Efecto de distintas mezclas maíz-avena sobre parámetros sanguíneos. (Effects of different corn-oat mixtures on blood parameters).

\begin{tabular}{|c|c|c|c|c|}
\hline & $\begin{array}{c}\text { T0 } \\
\text { Sin suplemento }\end{array}$ & $\begin{array}{c}\mathrm{T} 1 \\
80: 20\end{array}$ & $\begin{array}{c}\text { T2 } \\
50: 50\end{array}$ & $\begin{array}{c}\text { T3 } \\
20: 80\end{array}$ \\
\hline Promedio $\mathrm{NH}_{3}$ en plasma $\left(\mathrm{mg} \mathrm{dL}^{-1}\right)$ & $0,19 \pm 0,02^{\mathrm{a}}$ & $0,15 \pm 0,02^{\mathrm{a}}$ & $0,14 \pm 0,03^{a}$ & $0,17 \pm 0,03^{a}$ \\
\hline $\mathrm{NH}_{3}$ en plasma (5:00 a.m.) & $0,16 \pm 0,02^{\mathrm{a}}$ & $0,14 \pm 0,03^{a}$ & $0,13 \pm 0,02^{a}$ & $0,17 \pm 0,01^{\mathrm{a}}$ \\
\hline $\mathrm{NH}_{3}$ en plasma (4:00 p.m.) & $0,22 \pm 0,03^{a}$ & $0,15 \pm 0,01^{a}$ & $0,14 \pm 0,03^{a}$ & $0,15 \pm 0,02^{a}$ \\
\hline Promedio urea en plasma $\left(\left(\mathrm{mg} \cdot \mathrm{dL}^{-1}\right)\right.$ & $13,2 \pm 0,96^{\mathrm{a}}$ & $11,2 \pm 0,90^{\mathrm{a}}$ & $11,2 \pm 0,15^{\mathrm{a}}$ & $0,12,7 \pm 1,2$ \\
\hline Urea en plasma (5:00 a.m.) & $12,4 \pm 1,2^{\mathrm{a}}$ & $11,2 \pm 0,82^{a}$ & $10,4 \pm 0,93^{a}$ & $13,1 \pm 0,9^{a}$ \\
\hline Urea en plasma (4:00 p.m.) & $13,9 \pm 2,3^{a}$ & $11,2 \pm 0,74^{\mathrm{a}}$ & $11.9 \pm 0,91^{\mathrm{a}}$ & $13,3 \pm 0,9^{a}$ \\
\hline
\end{tabular}

aLetras iguales en la misma línea indican ausencia de diferencia $(p>0,05)$. 


\section{MANTEROLA, CARREÑO, ORELLANA, GONZÁLEZY CERDA}

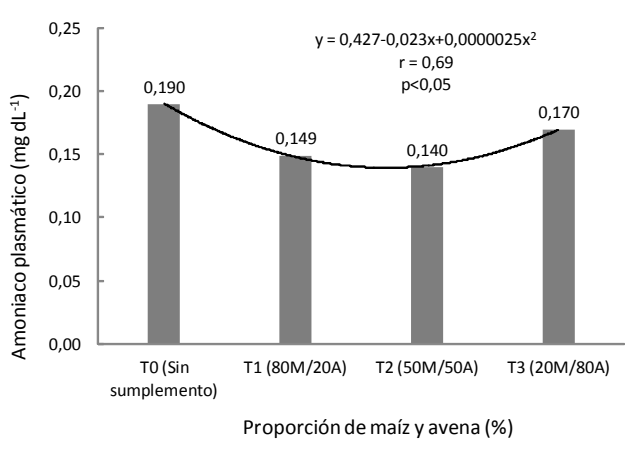

Figura 3. Concentración de amoniaco en plasma en vacas fistuladas y suplementadas con maíz y avena en distintas proporciones. (Plasma ammonia in fistulated dairy cows supplemented with corn and oat in different proportions).

como tampoco en aquellas variables relacionadas con la composición de la leche (tabla VI). No se encontraron diferencias significativas en la concentración de urea en leche, a pesar de las menores concentraciones de amoníaco en rumen determinadas en los tratamientos con suplementación, lo que coincide con lo reportado por Alvarez et al. (2006) quien obtuvo valores de urea en

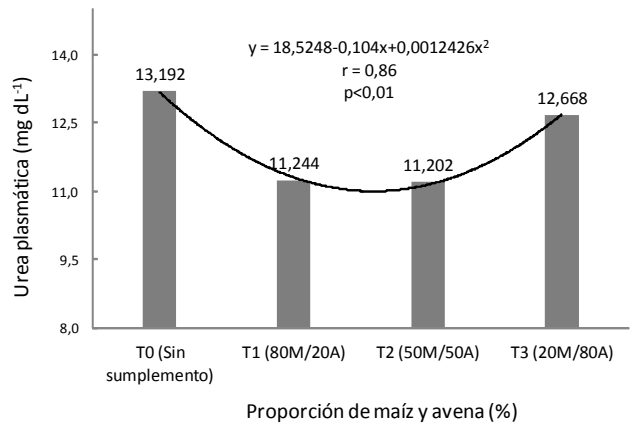

Figura 4. Urea en plasma en vacas fistuladas y suplementadas con distintas proporciones de maíz y avena. (Plasmatic urea in fistulated dairy cows supplemented with corn and oat in different proportions).

leche superiores a $30 \mathrm{mg} / \mathrm{dL}$, con niveles de baja y alta suplementación energética, sin encontrar descensos relevantes de urea en leche por efecto de tratamiento, y con lo reportado por Pulido et al. (2009) en vacas en pastoreo primaveral con diferentes niveles de suplementación energética, quienes encontraron niveles similares de urea en leche en los distintos tratamientos.

Tabla VI. Efecto de la suplementación con diferentes mezclas de maíz y avena sobre la producción y composición (media \pm error estándar) de la leche ${ }^{1}$. (Effect of supplementation with different mixtures of corn and oat on milk production and composition (media \pm standar error $\left.{ }^{1}\right)$ ).

\begin{tabular}{|c|c|c|c|c|}
\hline & $\begin{array}{c}\text { T0 } \\
\text { Sin suplemento }\end{array}$ & $\begin{array}{c}\text { T1 } \\
80: 20\end{array}$ & $\begin{array}{c}\text { T2 } \\
50: 50\end{array}$ & $\begin{array}{c}\text { T3 } \\
20: 80\end{array}$ \\
\hline Producción de leche $\left(\mathrm{kg}^{*} \mathrm{~d}^{-1}\right)$ & $23,4 \pm 0,9^{a} *$ & $20,8 \pm 0,8^{a}$ & $25,3 \pm 1,2^{a}$ & $24,3 \pm 0,8^{a}$ \\
\hline Contenido graso, \% & $4,7 \pm 0,4^{\underline{a}}$ & $4,6 \pm 0,4^{\underline{a}}$ & $4,7 \pm 0,4^{\underline{a}}$ & $4,6 \pm 0,4^{a}$ \\
\hline Contenido proteico, \% & $3,7 \pm 0,2^{\mathrm{a}}$ & $3,7 \pm 0,1^{a}$ & $3,6 \pm 0,1^{a}$ & $3,7 \pm 0,2^{\mathrm{a}}$ \\
\hline VEPTMJ/d & $81,4 \pm 3,1^{\mathrm{a}}$ & $71,1 \pm 2,7^{\mathrm{a}}$ & $87,7 \pm 3,6^{\mathrm{a}}$ & $83,4 \pm 3,3^{\mathrm{a}}$ \\
\hline PLCE, kg/d & $25,9 \pm 1,0^{\mathrm{a}}$ & $22,7 \pm 0,9^{a}$ & $27,1 \pm 1,1^{a}$ & $26,6 \pm 1,0^{a}$ \\
\hline PPROT,g/d & $864,3 \pm 32,4^{a}$ & $761,5 \pm 28,6^{\mathrm{a}}$ & $912,3 \pm 34,2^{\underline{a}}$ & $893,5 \pm 33,8$ \\
\hline PGRAS, g/d & $1092 \pm 40,9^{a}$ & $944 \pm 37,4^{\mathrm{a}}$ & $1188 \pm 44,6^{a}$ & $1110 \pm 41,6^{a}$ \\
\hline Urea en leche total $\left(\mathrm{mg}^{*} \mathrm{dL}^{-1}\right)$ & $32,9 \pm 1,9^{a}$ & $30,4 \pm 1,8^{a}$ & $29,2 \pm 1,5^{\mathrm{a}}$ & $31,8 \pm 1,7^{a} \underline{a}$ \\
\hline
\end{tabular}

${ }^{1}$ Promedio de los 4 periodos experimentales.

aLetras iguales en la misma línea indican ausencia de diferencia $(p>0,05)$, según la prueba de Tukey. $\mathrm{VEPT}=$ valor energético de la producción por día; $\mathrm{PLCE}=$ producción de leche corregida por energía; PPROT= producción de proteína; PGRAS: producción de grasa. 


\section{CARBOHIDRATOS, CAPTURA DE NITRÓGENO Y PRODUCCIÓN DE LECHE BOVINA}

\section{CONCLUSIONES}

La suplementación con mezclas de maíz y avena en distintas proporciones, a vacas en lactancia consumiendo pasturas de ballica perenne de alto contenido proteico, reduce significativamente la concentración de amoníaco ruminal, sin que esta reducción se traduzca en una menor concentra-

\section{BIBLIOGRAFÍA}

Alvarez, H.J.; Dichio, L.; Pece, M.A.; Cangiano, C.A. y Galli, J. 2006. Producción de leche bovina con distintos niveles de asignación de pastura y suplementación energética. Ciencia Invest Agr, 33: 99-107.

Bach, A; Casalmiglia, S. and Stern, M.D. 2005. Nitrogen metabolism in the rumen. J Dairy Sci, 88 (Suppl.1): E9-E21.

FIA-UACH. 1995. Composición de alimentos para el ganado en la zona sur. Universidad Austral de Chile. Fundación Fondo de Investigación Agropecuaria (Eds). Ministerio de Agricultura. Editorial Universitaria. Valdivia. Chile.

Frank, B.; Persson, M. and Gustafsson, G. 2002. Feeding dairy cows for decreased ammonia emission. Livest Prod Sci, 76: 171-179.

Gehman, A.M.; Bertrand, J.A.; Jenkins, T.C. and Pinkerton, B.W. 2006. The effect of carbohydrate source on nitrogen capture in dairy cows on pasture. J Dairy Sci, 89: 2659-2667.

Hristrov, A.N. and Ropp, J.K. 2003. Effect of dietary carbohydrate composition and availability on utilization of ruminal ammonia nitrogen for milk protein synthesis in dairy cows. J Dairy Sci, 86: 2416-2437.

Hristov, A.N.; Ropp, J.K.; Grandeen, S.A.; Etter, A.; Melgar, A. and Folley, A.E. 2005. Effect of carbohydrate source on ammonia utilization in lactating dairy cows. J Anim Sci, 83: 408-421.

Jahn, E.B.; Borquez, L.F.; Monsalve, M.I.; Contreras, G.; Ormeño, G. y Manterola, H. 1996. Influencia de dos ambientes ruminales en la degradación de avena y maíz grano y degradación de afrechillo de trigo, harinilla de arroz y coseta húmeda. Agricultura Técnica (Chile), 56: 270-277.

Keim, J.P. and Anrique, R. 2011. Nutritional strategies to improve nitrogen use efficiency by ción de urea en el plasma o en la leche.

La suplementación con mezclas de maíz y avena en diferentes proporciones, no afectan la producción de leche, el contenido graso, el contenido proteico ni el contenido de energía de la leche, así como tampoco la producción de grasa y la producción de proteína.

grazing dairy cows. Chilean J Agric Res, 71: 119.

Kolver, E.S. and Muller, L.D. 1998. Performance and nutrient intake of high producing Holstein cows consuming pasture or a total mixed ration. J Dairy Sci, 81: 1403-1411.

Orskov, E.R. and MacDonald, I. 1979. The estimation of protein degradability in the rumen from incubation measurements weighted according to rate of passage. J Agric Sci Camb, 92: 499-503.

Pulido, R.G.; Escobar, A.; Foller, S.; Leiva, M.; Orellana, P.; Wittwer, F. y Balocchi, O. 2009. Efecto del nivel de suplementación con concentrado sobre la respuesta productiva en vacas lecheras a pastoreo primaveral con alta disponibilidad de pradera. Arch Med Vet, 41: 197-204.

Reis, R.B. and Combs, D.K. 2000. Effects of increasing levels of grain supplementation on rumen environment and lactation performance of dairy cows grazing grass-legume pasture. $J$ Dairy Sci, 83: 2888-2898.

Robaina, A.C.; Grainger, C.; Moate, P.; Taylor, J. and Stewart, J. 1998. Responses to grain feeding by grazing dairy cows. Aust J Exp Agr, 38: 541-549.

Stokes, S.R.; Hoover, W.H.; Miller, T.K. and Blauwiekel, R. 1991. Balancing carbohydrates and protein for optimum rumen microbial yield. $J$ Dairy Sci, 74: 1215-1223.

Van Vuuren, A.M.; Tamminga, S. and Ketelaar, R.S. 1991. In sacco degradation of organic matter and crude protein of fresh grass (Lolium perenne) in the rumen of grazing dairy cows. $J$ Agr Sci Camb, 116: 429-436.

Valderrama, X. y Anrique, R. 2011. Cinética de degradación ruminal en forrajes de alto contenido proteico en clima templado. Chilean J Agric Res, 71: 572-577. 